\title{
Sistem informasi yang berkualitas di bpjs kesehatan Kota palembang
}

\author{
Venny Yusiana \\ Jurusan Teknik Listrik, Fakultas Teknik, Universitas Batanghari \\ ${ }^{*}$ Corresponding author, e-mail: vyusaki@yahoo.com
}

\begin{abstract}
Abstrak
Sistem informasi telah berkembang seiring dengan perkembangan teknologi yang sangat cepat dan terbukti dalam berbagai kegiatan. Adanya sistem informasi yang mendorong kinerja, efektivitas dan keragaman untuk berbagai institusi. Penelitian ini untuk melihat representasi sistem informasi mutu pada BPJS Kesehatan Kota Palembang berdasarkan variabel yang tepat. Hasil penelitian menunjukkan nilai variabel dalam sistem informasi kualitas menggunakan AMOS converter untuk metode SEM pada tahap awal.Kata Kunci :
\end{abstract}

\begin{abstract}
Information systems have evolved along with technological developments that are very fast and proven in various activities. The existence of information systems that encourage performance, effectiveness and variety for various institutions. This research is to see the representation of quality information system at Health BPJS Palembang city based on the right variables. The results of the research indicate the value of the variables in the quality information system using the AMOS converter for the SEM method in the early stages.

Keywords : DRV 11873, Speed (RPM), PWM duty cycle
\end{abstract}

\section{PENDAHULUAN}

Sistem informasi merupakan komponen yang terdiri dari manusia, teknologi informasi dan prosedur kerja yang memproses , menyimpan, menganalisa dan menyebarkan informasi untuk suatu tujuan [Mulyanto agus:2009].Salah satu perusahaan yang menggunakan sistem informasi yaitu BPJS (Badan Penyelenggara Jaminan Sosial) Kesehatan merupakan lembaga yang menyediakan pelayanan kesehatan masyarakat. Untuk dapat menilai sejauh mana kualitas pelayanan publik yang diberikan oleh aparat pemerintah, perlu ada kriteria yang menunjukan apakah suatu pelayanan publik yang diberikan dapat dikatakan baik atau buruk.

Adapun dasar untuk menilai suatu kualitas pelayanan selalu berubah dan berbeda. Apa yang dianggap sebagai suatu pelayanan yang berkualitas saat ini tidak mustahil dianggap sebagai sesuatu yang tidak berkualitas pada saat yang lain. Informasi yang berkualitas diartikan sebagai data yang diolah menjadi bentuk yang lebih berguna bagi yang menerimanya baik dari ketepatan waktu, relevansi dan akurasi.

Dengan memperhatikan kerangka teoritis dan tahapan penelitian yang telah dilakukan maka teknik yang digunakan dalam penelitian ini adalah model persamaan structural (Structural Equation Modelling/ SEM) berdasarkan komputasi AMOS. Dimana SEM menguji suatu rangkaian hubungan saling ketergantungan antar variable secara simultan pada tahap awal .

\section{TINJAUAN PUSTAKA}

Metode dalam penelitian ini adalah penelitian deskriptif dengan pendekatan kuantitatif. Suatu bentuk penelitian yang berdasarkan data yang dikumpulkan selama penelitian secara sistematis mengenai faktafakta dan sifat-sifat dari objek yang diteliti dengan menggabungkan hubungan antara variable yang terlibat didalamnya, kemudian diinterprestasikan berdasarkan teori-teori dan literature yang berhubungan dengan system informasi pelayanan publik yang berkualitas.

Penelitian ini menggunakan data primer yang diperoleh melalui pengamatan langsung dilapangan dengan berpedoman pada instrument penelitian menggunakan kuesioner dibuat dengan skala Likert, sedangkan data sekunder diperoleh dari berbagai laporan dan publikasi yang relevan dengan penelitian. 
Sample penelitian diambil dari beberapa tempat di kota Palembang secara random atau probability sampling dan nonprobability sampling dimana pengambilan samplenya berdasarkan karakteristik dari peserta BPJS. Karakteristik dari sample yang akan dijadikan responden dalam penelitian ini yaitu peserta BPJS kesehatan Kota Palembang yang berumur 17 tahun sampai 60 tahun dan bisa menggunakan internet. Dalam penelitian ini menggunakan SEM karena langsung berkaitan dengan hubungan ganda secara simultan sekaligus memberikan efisiensi analisis statika dan memberikan analisis exploratory menuju analisis confirmatory.

\section{METODOLOGI}

Metode dalam penelitian ini adalah penelitian deskriptif dengan pendekatan kuantitatif. Suatu bentuk penelitian yang berdasarkan data yang dikumpulkan selama penelitian secara sistematis mengenai faktafakta dan sifat-sifat dari objek yang diteliti dengan menggabungkan hubungan antara variable yang terlibat didalamnya, kemudian diinterprestasikan berdasarkan teori-teori dan literature yang berhubungan dengan system informasi pelayanan publik yang berkualitas.

Penelitian ini menggunakan data primer yang diperoleh melalui pengamatan langsung dilapangan dengan berpedoman pada instrument penelitian menggunakan kuesioner dibuat dengan skala Likert, sedangkan data sekunder diperoleh dari berbagai laporan dan publikasi yang relevan dengan penelitian. Sample penelitian diambil dari beberapa tempat di kota Palembang secara random atau probability sampling dan nonprobability sampling dimana pengambilan samplenya berdasarkan karakteristik dari peserta BPJS. Karakteristik dari sample yang akan dijadikan responden dalam penelitian ini yaitu peserta BPJS kesehatan Kota Palembang yang berumur 17 tahun sampai 60 tahun dan bisa menggunakan internet. Dalam penelitian ini menggunakan SEM karena langsung berkaitan dengan hubungan ganda secara simultan sekaligus memberikan efisiensi analisis statika dan memberikan analisis exploratory menuju analisis confirmatory.

\section{HASIL ANALISA PERCOBAAN}

Instrumen yang digunakan untuk menjelaskan informasi yang berkualitas dari sistem informasi di BPJS kesehatan kota Palembang yang terdiri dari 5 item pernyataan, dimana masing-masing pernyataan memiliki 5 buah alternative jawaban dengan rentang skor 1 sampai dengan 5 yang terdiri dari lima tingkatan yakni: sangat tidak setuju, tidak setuju, ragu-ragu, setuju dan sangat setuju.

Distribusi frekuensi jawaban kuesioner untuk variable informasi yang berkualitas disajikan pada tabel 1. Responden paling banyak memilih sangan setuju 40,9\%, hal ini menunjukan persepsi pengguna sangat setuju jika informasi yang berkualitas di BPJS dapat membantu system informasi pada pelayanan public. Berkaitan dengan kualitas pelayanan, Gronroos (1990) mendefinisikan pelayanan (service) sebagai suatu aktivitas atau rangkaian aktivitas, terjadi interaksi dengan seseorang atau mesin secara fisik dan penyediaan kepuasan pelanggan. 
Tabel 1.

Distribusi Frekuensi Jawaban Responden untuk Kriteria Informasi yg Berkualitas

\begin{tabular}{|c|c|c|c|c|c|c|}
\hline No & Pernyataan & STS & TS & $\mathbf{R} \mathbf{R}$ & $\mathbf{S}$ & SS \\
\hline 1 & $\begin{array}{l}\text { BPJS harus menggunakan jaringan } \\
\text { komputer }\end{array}$ & $2(1,3 \%)$ & $6(3,8 \%)$ & $6(3,8 \%)$ & $65(40,6 \%)$ & $81(50,6 \%)$ \\
\hline 2 & BPJS memberikan informasi yg akurat & $12(7,5 \%)$ & $5(3,1 \%)$ & $18(11,3 \%)$ & $60(37,5 \%)$ & $65(40,6 \%)$ \\
\hline 3 & BPJS memberikan informasi yg terbaru & $8(5 \%)$ & $6(3,8 \%)$ & $27(16,9 \%)$ & $64(40 \%)$ & $55(34,4 \%)$ \\
\hline 4 & $\begin{array}{l}\text { BPJS memberikan informasi yg } \\
\text { relevan dan terperinci }\end{array}$ & $7(4,4 \%)$ & $9(5,6 \%)$ & $37(23,1 \%)$ & $68(42,5 \%)$ & $39(24,4 \%)$ \\
\hline 5 & $\begin{array}{l}\text { Sistem informasi yg diterima pengguna } \\
\text { harus mudah dimengerti }\end{array}$ & $6(3,8 \%)$ & $3(1,9 \%)$ & $8(5 \%)$ & $56(35 \%)$ & $87(54,4 \%)$ \\
\hline & Rata-rata & $7(4,4 \%)$ & $5,8(3,6 \%)$ & $19,2(12 \%)$ & $62,6(39,1 \%)$ & $65,4(40,9 \%)$ \\
\hline
\end{tabular}

Sumber : Data Primer Setelah Diolah

Pemeriksaan asumsi yang melandasi Structural Equation Modelling (SEM) adalah meliputi uji outlier, linieritas, validitas dan reabilitas. SEM adalah teknik statistic multivariate yang merupakan kombinasi antara analisis factor dan analisis regresi (korelasi) yang bertujuan untuk menguji hubunganhubungan antar variable yang ada pada sebuah model, baik itu antar indikator dengan konstruknya ataupun hubungan antar konstruk (Santoso,2014).

Data yang digunakan dalam penelitian akan mengandung outliers apabila data bersifat bias atau tidak berkualitas. Secara deskriptif berdasarkan mean dan standar deviasi (dengan bantuan software SPSS) diperoleh bahwa untuk semua indikator penilaian memiliki nilai mean yang lebih besar dibanding dengan standar deviasi sehingga semua indikator tidak mengandung data outliers.

Tes linearitas merupakan persyaratan penting untuk melakukan prosedur analisis faktor, dapat diperoleh dengan metode grafis dan metode statistik. Gambar 1. Menunjukan hasil analisis regresi yang menampilkan normal P-P plot item untuk informasi yang berkualitas.

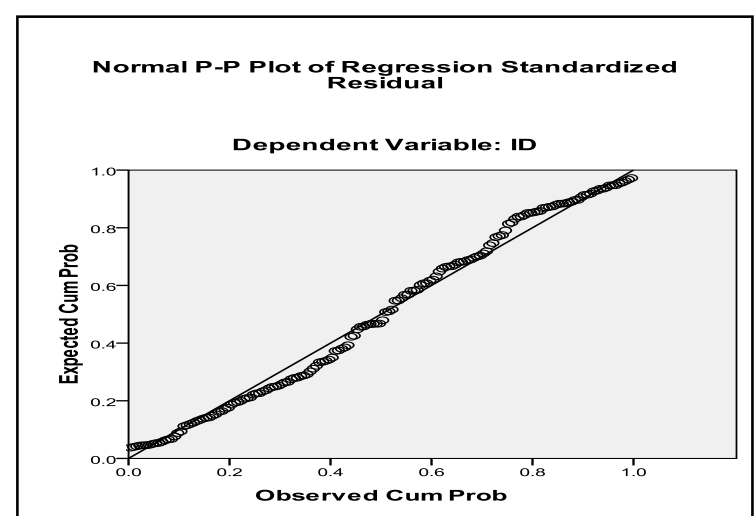

Gambar 1. Uji Linieritas

Uji validitas bertujuan untuk mengukur apa yang akan diukur atau alat ukur yang digunakan mengenai sasaran. Menurut Sugiyono (2014) syarat minimum untuk memenuhi validitas adalah apabila $r=0,3$ jika korelasi antara butir dengan skor $<0,3$ maka butir instrument tersebut dinyatakan tidak valid. Uji validitas dilakukan dengan melihat nilai Corrected ItemTotal Correlation. Hasil uji validitas dapat dilihat pada tabel 2 dimana item pernyataan kuesioner semuanya memiliki nilai $r>0,25$.

Tabel.2. Hasil Uji Validitas

\begin{tabular}{lccc}
\hline \multicolumn{1}{c}{ Variabel } & Indikator & $\begin{array}{l}\text { Corrected } \\
\text { Item-Total } \\
\text { Correlation }\end{array}$ & Keterangan \\
\hline Informasi yg & $\mathrm{X} 1$ & .486 & Valid \\
Berkualitas & $\mathrm{X} 2$ & .617 & Valid \\
& $\mathrm{X} 3$ & .715 & Valid \\
& $\mathrm{X} 4$ & .674 & Valid \\
& $\mathrm{X} 5$ & .613 & Valid \\
\hline
\end{tabular}

Sumber : Data Primer Setelah Diolah 


\subsection{Confirmatory Factor Analysis (CFA)}

Confirmatory Factor Analysis (CFA) Measurement Model digunakan untuk menguji sebuah measuremen model. Dengan alat ini, akan diketahui apakah indikator-indikator yang ada memang benar-benar dapat menjelaskan sebuah konstruk. Dengan melakukan CFA, dapat saja sebuah indikator dianggap tidak secara kuat berpengaruh atau dapat menjelaskan sebuah konstruk (Santoso,2012).

Terdapat dua uji dasar dalam $C F A$, yaitu uji kesesuaian model (Goodness-of- Fit Test) serta uji signifikansi bobot faktor. Uji kesesuaian model (Goodness-of- Fit Test) beberapa indeks kesesuaian dan cut-off value untuk menguji apakah sebuah model dapat diterima atau ditolak. Pengujian dilakukan dengan menggunakan pendekatan indeksindeks yang telah umum digunakan antara lain (H.Dedi Rianto, 2013) :

Tabel 3. Goodness of-fit Indices

\begin{tabular}{cc} 
Goodness of fit index & Cut-off Value \\
\hline$\chi^{2}-$ Chi-square & $\begin{array}{c}\text { Diharapkan } \\
\text { kecil }\end{array}$ \\
Sign.Probability & $\geq 0.05$ \\
CMIN/DF & $\leq 2.00$ \\
GFI & $\geq 0.90$ \\
AGFI & $\geq 0.90$ \\
TLI & $\geq 0.95$ \\
CFI & $\geq 0.95$ \\
RMSEA & $\leq 0,08$ \\
\hline
\end{tabular}

Informasi yang berkualitas terdiri dari lima variabel indikator yaitu X1 (Informasi yang akurat), X2 (Informasi terbaru), X3 (Informasi yang relevan), X4 (Informasi yang terperinci), X5 (Informasi yang mudah dimengerti). Setiap item terkait dengan kesalahan pengukuran berlabel dari e1 ke e5. Gambar 2 dibawah ini menunjukan perkiraan satu faktor model pengukuran awal dari Informasi yang berkualitas.

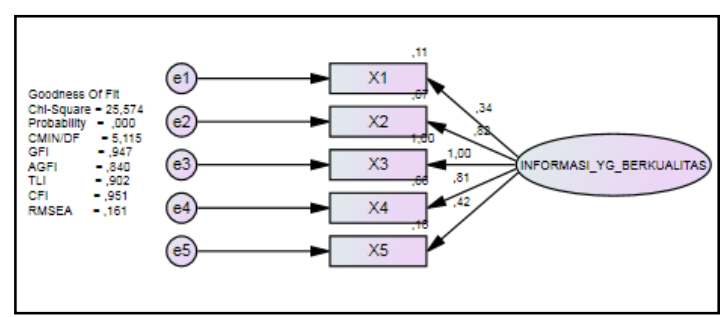

Gambar. 2. Konstruk Tahap Awal Variabel Informasi Yg Berkualitas

Hasil uji konstruk tahap awal variabel Informasi yang berkualitas disajikan pada Gambar 2. diatas dievaluasi berdasarkan goodness of fit indices pada tabel 4.14. berikut dengan disajikan kriteria model serta nilai kritisnya yang memiliki kesesuaian data.

Tabel 4. Indeks Pengujian kelayakan CFA KonstrukTahap Awal Variabel informasi Yg Berkualitas

\begin{tabular}{|c|c|c|c|c|c|c|}
\hline GO & CMIN & GF & AG & TL & CF & RM \\
F & /DF & I & FI & I & I & $\begin{array}{c}\text { SE } \\
\text { Ind }\end{array}$ \\
\cline { 2 - 7 } ex & 5.115 & 0.9 & 0.8 & 0.9 & 0.9 & 0.16 \\
& & 47 & 40 & 02 & 51 & 1 \\
\hline
\end{tabular}

erdasarkan tabel 4. maka dapa menunjukan model yang dilakukan tidak memiliki validitas yang memadai, hal ini diperlihatkan oleh nilai cut-off value yang lebih rendah dari nilai yang direkomendasikan seperti nilai CMIN/DF, AGFI,TLI dan RMSEA. Oleh karena itu berdasarkan literatur (Ferdinand, 2002, Dedi Rianto,2013), petunjuk modification indices kemudian perlu dilakukan modifikasi untuk memperbaiki model sehingga valid untuk pembuktian hipotesis. Modifikasi model diutamakan hanya pada korelasi antar item dan atau error dan tidak memodifikasi jalur pengaruh.

Tabel 5. Loading Factor Dari Setiap Indikator Variabel Informasi Yg Berkualitas

\begin{tabular}{cc}
\hline Indikator & Loading Factor \\
\hline X1 & 0,336 \\
X2 & 0,820 \\
X3 & 1,002 \\
X4 & 0,814 \\
X5 & 0,425 \\
\hline
\end{tabular}


Berdasarkan fakta empiris seperti pada Tabel 5. dapat dikatakan bahwa faktor loading pada indicator X1 dan X5 lebih rendah dari nilai yang direkomendasikan Sigih susanto, 2012 (>0.5), oleh karena itu indicator X1 dan X5 dihapus dari model pengukuran. Model ini akan di uji ulang setelah setelah menghapus variabel indicator X1 dan X5. Model pengukuran yang dihasilkan setelah menghapus variabel indicator X1 dan X5 ditunjukan pada gambar 3. dan tabel 6 .

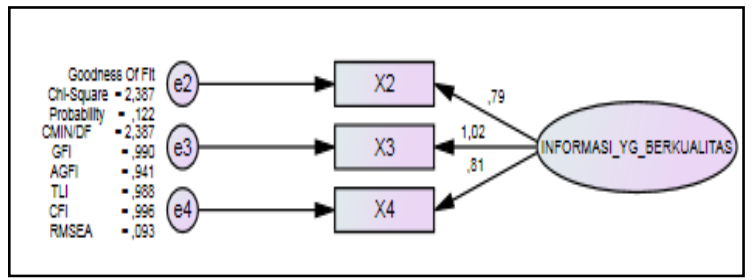

Gambar. 3 Konstruk Tahap Akhir Variabel Informasi Yg Berkualitas

Tabel 6. Indeks Pengujian kelayakan CFA KonstrukTahap Akhir Variabel informasi Yg Berkualitas

\begin{tabular}{|c|c|c|c|c|c|c|}
\hline GO & CMIN & GF & AG & TL & CF & RMS \\
F & /DF & I & FI & I & I & EA \\
\cline { 2 - 7 } Ind & 2.387 & 0.9 & 0.9 & 0.9 & 0.9 & 0.093 \\
ex & & 90 & 41 & 88 & 96 & \\
\hline
\end{tabular}

Tabel 7. Loading Factor Dari Setiap Indikator Variabel Informasi Yg Berkualitas

\begin{tabular}{cc}
\hline Indikator & Loading Factor \\
\hline X2 & 0,786 \\
X3 & 1,020 \\
X4 & 0,814 \\
\hline
\end{tabular}

Dari evaluasi model yang diajukan menunjukkan bahwa evaluasi model terhadap konstruk secara keseluruhan menghasilkan nilai loading factor diatas nilai yg direkomendasikan (Susanto,2013) dan menunjukkan bahwa model telah sesuai dengan data, sehingga dapat dilakukan uji kesesuaian model selanjutnya.

\section{SIMPULAN}

Hasil dari penelitian ini menunjukan nilainilai dari CFA (Confirmatory factor analysis) memberi petunjuk bahwa ada beberapa hasil yang terlihat tidak memenuhi standar yang di harapkan, sehingga variabel penentu kualitas informasi pelayanan publik tidak semuanya memuaskan. Hal ini dilakukan pada tahap pengujian awal berdasarkan komputasi AMOS untuk model SEM, sedangkan untuk pengujian selanjutnya di perlukan variabel yang lebih lengkap untuk melihat hubungan antar variable untuk memdapatkan nilai yang diharapkan.

\section{DAFTAR PUSTAKA}

[1] Bhisma Murti, "Contracting Out Pelayanan Kesehatan: Sebuah Alternatif Solusi Keterbatasan Sektor Plus,"Jurnal Manajemen pelayanan Kesehatan , Vol 09,No.3, September 2006.

[2] Barnes.S.J \& Vidgen.R, ". An Evalution Of Cyber bookshops: the webqual method,International Journal of Electronic Commerce. G(1).11-30, 2001.

[3] DR.Dedi Rianto Rahadi, ". Peranan Teknologi Informasi Dalam Peningkatan Pelayanan Di Sektor publik,"Seminar Nasional Teknologi Yogyakarta,ISSN :1978-9777, 24 November, 2007.

[4] D. Antoni and F. Jie, "The relationship between IT capability and organizational environment performance: A conceptual framework," in 3rd Annual international Conference on Infocomm Technologies in Competitives strategies (ICT 2012), ed. Bali, 2012, p. 47.

[5] Erick.S.Holle, "Pelayanan publik melalui Elektronic government Upaya Meminilisir Praktek Maladministrasi Dalam Meningkatkan Public Service," Jurnal Sasi, vol. 17, No.3,JuliSeptember 2011.

[6] Erlyn Purba, "Analisis Tingkat Kepuasan Pelayanan Publik Pada Puskesmas Loa Janan," ISSN : 0216-6437, 2012.

[7] Evi Prismawati, "Analisis Kinerja Pelayanan Publik (Studi Kasus Pada SKPD kabupaten Sukoharjo)," skripsi, 2010.

[8] Enceng dan Yuli Tirtariandi El Anshori, "Kesenjangan Dalam Pelayanan Publik," Jurnal 
Administrasi Pembangunan, vol. 1, No.2, hlm 101-218,Maret 2013.

[9] E Satriya, "Pentingnya Revitalisasi egovernment di Indonesia," konfrensi Nasional Teknologi Informasi , 2006.

[10] Hizkia Paat, "Kualitas Pelayanan Publik Di Kecamatan Motoling Kabupaten Minahasa Selatan," IT Professional, Proposal Tesis 2013.

[11] H. Yang and M. Tate, "Where are we at with cloud computing?: a descriptive literature review," 2009.

[12] I Maliki , "Manajemen Resiko Teknologi informasi Untuk Keberlangsungan Layanan publik Menggunakan Framework Information," Seminar Nasional Aplikasi Teknologi Informasi,SNATI, 2010.

[13] Kanishka Karunasena, Hepu Deng, "Critical Factors for evaluating the public value of e-government in Sri Langka," Journal homepage:www.elsevier.com/locate/govint.

[14] Khusnul Khasanah, "Pengaruh Motivasi Pelayanan Publik Terhadap Kinerja pegawai Badan Perizinan Terpadu dan Penanaman modal Di Kota Makasar," Skripsi, 2015.

[15] Kanishka Karusena,Hepu Deng,Mohini Singh,"Transforming Government: People,Process and Policy," Emerald Article: Measuring the public value of e-government : a case study from Sri langka, 2011.

[16] Muhammad Ali bin Embi, Rita Widyasari, "Teori dan Model Pengukuran Kepuasan Masyarakat Terhadap Keberkesanan Sistem Pelayanan Publik," Tingkap, vol. IX, No.2, 2013. 